dislodged and get attached to fantasies of childhood like iron filings on a magnetic field. Because age regression techniques involve many pitfalls one should not generalise that all hypnotherapy techniques are bogus. Unfortunately, the media and entertainment industry often portrays hypnotherapists regressing all their clients to younger days. Introducing a more efficient code of practice and special registration to practise hypnotherapy would be more constructive than debunking hypnosis.

Branden, S., Boakes, J., Glaser, D., et al (1988) Recovered memories of childhood sexual abuse. Implications for clinical practice. British journal of Psychiatry, 172, 296-307.

Dingwall, J. E. (1967) Abnormal Hypnotic Phenomenon ( 4 vols). London: Churchill.

Stevenson, I. (1997) Reincarnotion and Biology. A Contribution to the Etiology of Birthmorks and Birth Defects ( 2 vols). London: Prager.

J. Paul Kingswood Mental Health Centre, Union Street, Maidstone, Kent MEI4 IEY

Sir: Awareness of the dangers of implanting false memories of childhood sexual abuse must be widespread by now and the recommendations with which Brandon et al (1998) conclude their paper will be generally accepted. It is, therefore, a pity that they were not more balanced in presenting the evidence concerning the recovery of forgotten memories. In a paper in this journal Brewin (1996) concluded that there was both experimental and clinical evidence that memories can be recovered from total amnesia and that they may be essentially accurate. It is not clear why Brandon et al did not discuss this paper nor why they interviewed only 'retractors' and accused parents. There is also, I believe, a basic inconsistency in their position; why, if false memories can be implanted, and if it is accepted that people may "be unable to remember considerable parts of their past experiences", should not the inability to recall what actually occurred ('false forgetting') also be induced?

Memory is not held only in the head; the constructions, reconstructions and fallibility of autobiographical memory are the products of the individual in relation to his or her social and personal context. The injunctions of abusers to keep silent, the interpretations of memories of abuse as fantasy by psychoanalysts and the social taboo on discussing the issue combined for a long time to make memories of abuse unsayable and in some instances unremem- berable. Psychotherapists working in the late 1970 s and 1980 s met many more patients than previously who remembered childhood abuse, once the issue had been aired in the media. Since then, I have carried out or supervised the treatment of a great many patients receiving a form of therapy which does not ferret after or suggest hidden memories. I have encountered a very small number of cases in whom memories were recovered from complete amnesia and a very large number who, once a therapeutic alliance had been established, revised and extended their memories in terms of the timing, details, meaning and associated emotions of partially remembered abuse. Many of these patients sought and found corroboration of these memories, most often from siblings.

While it is crucial that professionals avoid implanting false memories of sexual abuse and important to assess such memories judiciously, responsible clinicians must also recognise the ways in which memories recovered from partial or total amnesia may, and in most cases do, refer to actual experience. To paraphrase Brandon et al, there is abundant evidence that false forgetting occurs, and it is important that clinicians do not reinforce it in the many individuals whose experiences need, but have never been granted, acknowledgement.

Brandon, S., Boakes, J., Glaser, D., et ol (1998) Recovered memories of childhood sexual abuse. implications for clinical practice. British journol of Psychiotry, 172. 296-307.

Brewin, C. R. (1996) Scientific status of recovered memories. British journal of Psychiatry, 169, |31-134.

A. Ryle ACAT Office, Munro Clinic, Guy's Hospital, London SE] 9RT

Authors' reply: We should have made it clear that the literature review which we made was much more exhaustive than the reference list to our paper might suggest. The material was so voluminous and much of it of such poor scientific quality that, space considerations apart, much of it did not justify a reminder of its existence and we confined ourselves to that which was essential to our argument.

It is true that we confined our references to hypnosis to a single book but this was such a rich source of further references that we deemed it sufficient.

We quite accept that patients report and psychiatrists hear what conforms with their beliefs and the social milieu. Many patients go through life never mentioning abuse which occurred in childhood. The setting up of ChildLine resulted in some women in their 70 s and 80 s ringing up to talk about their childhood abuse for now 'that it was out in the open' they could talk of the pain they had carried throughout their lives. Men who were Japanese prisoners of war when recently interviewed gave horrific and detailed accounts of their suffering which they had never felt able to mention to anyone who had not shared the experience. Their families knew nothing of what had occurred. Many memories suppressed or avoided for years can come forward following a related emotional trauma or within a trusting relationship.

We did not specifically discuss Professor Brewin's paper but believe that most of the points he made are covered within our review. We disagree with him on some matters but his conclusions are much the same as ours. False beliefs and false memories can occur and extreme caution must be observed when new 'memories' emerge whether during or outside a therapeutic intervention.

We are somewhat perplexed by 'false forgetting' and cannot imagine how it could be proved. People continually forget and remember things. What is at issue and is the key area for clinicians is the creation of new and false memories through unsound beliefs and unsafe practices. The mounting body of evidence of such practices among psychiatrists and established therapists as well as among 'fringe' practitioners is in danger of discrediting psychiatry in general and psychotherapy in particular.

We sincerely hope that the guidelines published in the Bulletin (Royal College of Psychiatrists' Working Group on Reported Recovered Memories of Childhood Sexual Abuse, 1997) will enable psychiatrists and others to stem the tide of these potentially harmful practices.

Royal College of Psychiatrists' Working Group on Reported Recovered Memorles of Childhood Sexual Abuse (1997) Recommendations for good practice and implications for training, continuing professional development and research. Psychictric Bulletin, 21, 663-665.

S. Brandon University of Leicester, Post Graduate Dean's Office. Royal Infirmary, PO Box 65, Leicester LE2 7LX

J. Boakes St George's Hospital, London

Sir: Brandon et al (1998) have produced a commendably careful, comprehensive and 
balanced report on the evidence with regard to recovered memories of childhood sexual abuse. The report's conclusions and guidance clearly suggest that some clinical practices carry an especially high risk of inducing illusory memories, with potentially harmful consequences to patients and their families. As these practices involve the imposition of the clinician's beliefs upon the patient, with no proven benefits and a distinct risk of harm, they can only be regarded as potentially or actually abusive and unethical.

The Royal College of Psychiatrists has a long history of principled opposition to unethical practice, particularly with respect to political abuse of psychiatry in South Africa and the Soviet Union. We are therefore puzzled by the College's failure to endorse fully its working group's report. This apparent equivocation has been widely reported in the national press, and has created an impression that evidence (rather than opinion) may exist which contradicts the report's main conclusions. This undermines the credibility of these important findings and recommendations. In order to resolve this ambiguity, we call upon the President of the College to explain why the full report was not published under the College's imprimatur.

Brandon, S., Boakes, J., Glaser, D., et ol (1998) Recovered memories of childhood sexual abuse. Implications for clinical practice. British journol of Psychiotry, 172, 296-307.

R. Poole, R. Higgo North Mersey Community (NHS) Trust, Acute Directorate, Broadoak Unit,

Thomas Drive, Liverpool LI4 3PJ

President's reply: Drs Poole and Higgo ask why the original report of Professor Brandon's working party on recovered memories of childhood sexual abuse was not published under the College's imprimatur. Although the sequence of events was rather complex the explanation is quite straightforward.

The Executive and Finance Committee of the College (a sub-committee of Council) originally decided to establish a working group to draft a College report on the false or recovered memory syndrome in July 1994. Professor Brandon was invited to chair the working group and nominations for its other members were invited from the then General Psychiatry, Child and Adolescent Psychiatry, Forensic Psychiatry and Psychotherapy Sections of the College. It was subsequently decided, in view of its predominant interest in the topic, that the Psychotherapy Section should have two representatives. As a result the working group eventually had six members.

The working group's draft report was first seen by the Executive and Finance Committee on 13 September 1996 and it was clear that it was contentious. One of the two representatives of the Psychotherapy Section was dissociating himself from the report, the Executive Committee of the Psychotherapy Section was disturbed by some of its conclusions, and those conclusions were significantly different from those previously published by the British Psychological Society and the American Psychiatric Association. For this reason comments on the report were solicited from the Psychotherapy and Forensic Psychiatry Sections and Professor Brandon and his colleagues were asked to consider revising their report in the light of those comments.

After a further meeting of the working group Professor Brandon returned to the meeting of the Executive and Finance Committee on 10 January 1997 and proposed that, as his working group was still unable to produce a report on which consensus could be achieved, either within its own membership or within the College's wider membership, the College should restrict itself to issuing guidelines on good practice in this area (including recommendations for training and future research) as this was the most urgent need. This very sensible proposal was accepted by the Committee and it was agreed at the same time that Professor Brandon and his colleagues would be free to publish the other, more contentious parts of their draft report under their own names wherever they wished. One possibility that was discussed was a book published under the Gaskell imprint.

The working group then reconvened and was able to reach unanimous agreement on a set of guidelines on good practice which were subsequently accepted by Council, subject to a few minor changes in wording, at its meeting on 28 April 1997. Those guidelines were published under the College's imprimatur in the October 1997 issue of the Psychiatric Bulletin (Royal College of Psychiatrists' Working Group on Reported Recovered Memories of Child Sexual Abuse, 1997) and have been widely welcomed. The following month (i.e. in November 1997) Professor Brandon and three of his original five colleagues submitted the article referred to by Drs Poole and Higgo to the editor of the British Journal of Psychiatry, where it was published in April this year.

Royal College of Prychlatrists' Working Group on Reported Recovered Memorles of Child Sexual Abuse (1997) Recommendations for good practice and implications for training. continuing professional development and research. Psychiotric Bulletin, 21, 663665.

R. E. Kendell President, Royal College of

Psychiatrists, 17 Belgrave Square, London SWIX 8PG

\section{Antidepressant quandaries}

Sir: Moncrieff et al (1998) and Healy (1998) provide thought-provoking articles comparing treatment outcomes for antidepressants and active placebos. The findings documenting fragility of antidepressant effects parallel concerns my colleagues and $I$ have raised in several publications analysing the antidepressant literature (e.g. Greenberg \& Fisher, 1989, 1997). Of paramount importance is the researchsupported conclusion that ratings of drug effectiveness relative to placebo decrease as blindness increases. It is, therefore, critical to check that the double-blind design is truly double-blind. Surprisingly, this is rarely verified. Almost all investigators simply assume that using a double-blind design guarantees blindness. In gathering evidence about validity for this assumption, we located about 30 studies attempting to discover whether the double-blind was breached. It was disconcerting to discover that the double-blind was penetrated in about $90 \%$ of the reports. The data provided in the typical double-blind psychotropic drug trial appear to be tainted and estimates of effectiveness likely inflated.

How is unblinding accomplished? Although it is possible that unblinding might be facilitated by active drugs producing more beneficial effects than placebos, at least equally plausible is the idea that differential levels of side-effects between drugs and placebos serve as the tip off. This is the reason why active placebos (those that produce bodily sensations) may be helpful in preserving blindness. In further support of this idea is a meta-analysis we published which was not cited by Moncrieff et al (1998) or Healy (1998). This work analysed the results of all available placebo-controlled double-blind studies of fluoxetine (Greenberg et al, 